\title{
OCEANOGRAPHIC CRUISE SUMMARY ROSS SEA, ANTARCTICA
}

\author{
DECEMBER 1967
}

This document has been approved for public

release and sale; its distribution is unlimited.

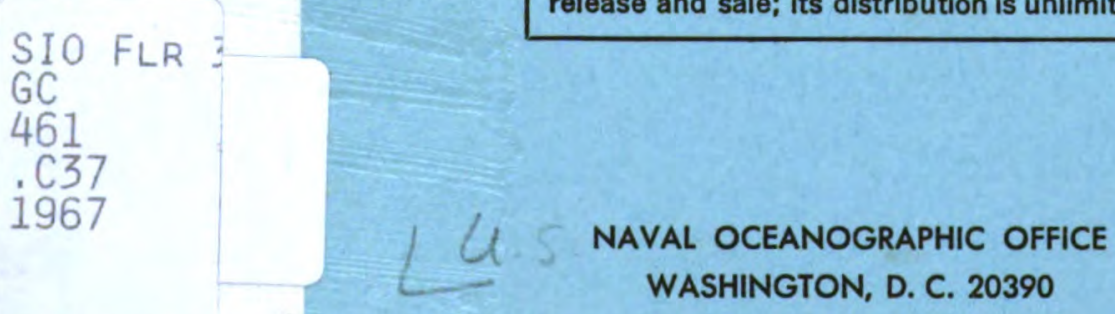

WASHINGTON, D. C. 20390 